\title{
Detection of sub-pptv benzene, toluene, and ethylbenzene via low- pressure photoionization mass spectrometry
}

\author{
Zhen $\mathrm{Li}^{\mathrm{a}}{ }^{\mathrm{b}}, \mathrm{Ce} \mathrm{Xu}^{\mathrm{a}}{ }^{\mathrm{b}}$, Jinian Shu ${ }^{\mathrm{a}}$, b, * \\ a State Key Joint Laboratory of Environment Simulation and Pollution Control, Research Center for Eco-Environmental Sciences, Chinese Academy of \\ Sciences, Beijing 100085, China \\ ${ }^{\mathrm{b}}$ University of Chinese Academy of Sciences, Beijing, China
}

\section{H I G H L I G H T S}

- LPPI mass spectrometry were demonstrated to be ultrasensitive for realtime detection.

- The obtained LODs are superior to those of other competitive techniques.

- Limits of detection for benzene, toluene, and ethylbenzene are 0.5 -0.8 pptv.

- Detection sensitivities for benzene, toluene, and ethylbenzene are 4-7 counts/pptv.

- Reliable accuracy and precision are demonstrated in two calibration methods.

\section{A R T I C L E I N F O}

\section{Article history:}

Received 24 November 2016

Received in revised form

26 January 2017

Accepted 28 January 2017

Available online 7 February 2017

\section{Keywords:}

Sub-pptv

LOD

Ultrasensitive

LPPI-MS

\section{G $R$ A P H I C A L A B S T R A C T}

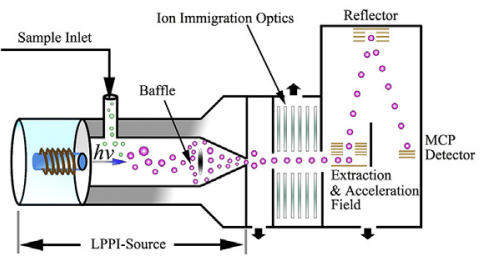

\begin{abstract}
A B S T R A C T
This paper reports on the advanced development of an ultrasensitive method for the detection of benzene, toluene, and ethylbenzene (or BTE) by low-pressure photoionization mass spectrometry (LPPI-MS). The LPPI source is composed of a laboratory-assembled krypton lamp and a stainless steel cylindrical ionizer. A compact V-shaped mass spectrometer is coupled to the LPPI source with a set of ion immigration optics under dc bias. The fixed standard concentration (FSC) and fixed standard volume (FSV) method are employed to calibrate the sensitivities of the instrument. The corresponding detection sensitivity toward BTE is $4-7$ counts/pptv and the $2 \sigma$ limit of detection (LOD) is $0.5-0.8$ part per trillion by volume (pptv). In addition, the measurement accuracy is $95 \%-105 \%$, and the corresponding precision ranges from $3 \%$ to $15 \%$ and from $9 \%$ to $31 \%$ for the FSC and FSV methods, respectively. The stability (standard deviation) of LPPI-MS for a 1 ppbv BTE mixture is less than $0.025(>12 \mathrm{~h}$ ). In the detection of BTE, water in ambient air is the most significant interfering factor, leading to the increased background, and inferior LODs of 1-2 pptv for BTE under an RH of $\sim 90 \%$ is observed. Experimental results indicated that LPPI-MS is reliable for the detection of sub-pptv levels of BTE under laboratory conditions.
\end{abstract}

๑) 2017 Elsevier B.V. All rights reserved.

\footnotetext{
* Corresponding author. Research Center for Eco-Environmental Sciences, Chinese Academy of Sciences, China.
}

E-mail address: jshu@rcees.ac.cn (J. Shu).

\section{Introduction}

Benzene, toluene, and ethylbenzene, collectively known as BTE, are common toxic volatile organic compounds (VOCs) existing in 
the production of petroleum, plastics, synthetic fibers, and pesticides [1]. In addition, BTE ubiquitous in urban atmosphere, posing substantial toxic health effects (e.g., mutagenic, carcinogenic stress and neurological, respiratory, excretory system damage) [2] and tremendously contribute to the smog photochemical reactions, influencing ozone in the troposphere [3]. For diagnostic purposes, BTE are considered as xenobiotic biomarkers in the breath of smokers [4].

Various real-time continuous analytical approaches have been developed to detect BTE. Ion mobility spectrometry (IMS) is the most portable and widespread method for the trace detection of aromatic compounds [5]. IMS usually equipped with a radioactive ionization source or an UV-lamp [6]. Although the ionization methods of these two kinds of ionization sources are different, their limit of detections (LODs) are similar, as low as several part per billion by volume for BTE [7-9]. The sensitivity of IMS is susceptible to the ambient moisture level and diverse constituents due to the influence of water and competing ion-molecule reactions [10]. The same situation occurs in atmospheric-pressure chemical ionization mass spectrometry (APCI-MS). The sensitivity of analytes with a lower proton affinity (PA) (e.g. PA benzene $=750 \mathrm{~kJ} / \mathrm{mol}$ ) is subject to be suppressed by higher ones (e.g. PA toluene $=784 \mathrm{~kJ} / \mathrm{mol}$, PA ethylbenzene $=799 \mathrm{~kJ} / \mathrm{mol}$ ), along with high background signals from protonated solvent molecules [11]. When employing corona discharge $(\mathrm{CD})$ as an atmospheric ionization source, the generation of $\mathrm{H}_{3} \mathrm{O}^{+}\left(\mathrm{H}_{2} \mathrm{O}\right)_{\mathrm{n}}$ and $\mathrm{NO}^{+}\left(\mathrm{H}_{2} \mathrm{O}\right)_{\mathrm{n}}$ reactant ions can be markedly enhanced, leading to the LODs of $\sim 400$ part per trillion by volume (pptv) for BTE [12]. Proton-transfer-reaction mass spectrometry (PTR-MS) is another kind of chemical ionization based technique. In spite of the ionization efficiency in PTR is slightly lower than in APCI, PTR-MS could achieve superior LODs of $\sim 10$ pptv for BTE, by using high-density of $\mathrm{H}_{3} \mathrm{O}^{+}$[13-15]. For higher mass resolution, time-of-flight (TOF) mass spectrometer used to be coupled with PTR. However, inferior LODs are observed, attributed to the loss of ions $[13,16]$.

Photoionization (PI) technologies are known for the soft ionization. Recently, the detection performance of PI methods has been largely improved [17-19]. Photoionization mass spectrometry (PIMS) could be a reliable alternative to IMS and PTR-MS. Laser-based resonance-enhanced multi-photon ionization (REMPI) is highly sensitive and selective for soft ionization of aromatic hydrocarbons, affording the LODs of $\sim 10$ pptv for BTE $[4,20]$. Nevertheless, the specific but limited analyte classes restrained the wide application of REMPI-MS. On the contrary, single-photon ionization (SPI) is able to soft ionize all organic compound classes [21]. The ionization efficiency in SPI is determined by the photon ionization crosssection $\left(\sigma_{\mathrm{spi}}\right)$ of the analyte, which affords better quantification by SPI as compared with that by other ionization methods [17]. Whereas, traditional SPI is limited to high vacuum condition and higher LODs ( 10 ppbv) [22,23]. Atmospheric pressure PI (APPI) is a relatively new technique, allowing direct SPI at ambient pressure [17]. The LODs of APPI-MS for BTE are $~ 500$ pptv [24]. Low-pressure PI (LPPI) is another relatively new method based on SPI, which is conducted under a pressure of hundreds pascals [25]. LPPI-MS has been confirmed as a rapid and ultrasensitive instrument for realtime monitoring of trace VOCs in previous studies, with the LODs of $\sim 5$ pptv for BTE [26]. Furthermore, LPPI can be more readily coupled to a TOF analyzer for higher resolution, without excessive loss of ions [17].

In this paper, the latest development in the detection of BTE by LPPI-MS is described. The detection sensitivity toward BTE is 4-7 counts/pptv. The corresponding $2 \sigma$ LODs for BTE are $0.5-0.8 \mathrm{pptv}$ under nitrogen and 1-2 pptv under 90\% RH. The accuracy and precision of the instrument are evaluated by two calibration methods. Detailed methods and experimental results are described

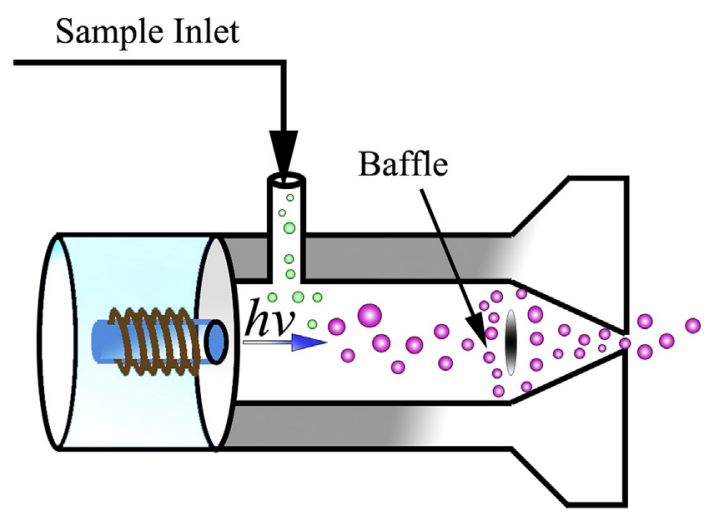

Fig. 1. Schematic drawing of LPPI-Source.

in following sections.

\section{Materials and methods}

\subsection{Instrumentation}

Fig. 1 shows the structure and mechanism of our self-developed LPPI source, which mainly consists of a Kr vacuum ultraviolet (VUV) lamp and a highly efficient photoionizer with an optical baffle. The output of the lamp is approximately $5 \times 10^{14}$ photon $\mathrm{s}^{-1}$ with energies of $10.0 \mathrm{eV}(\sim 80 \%)$ and $10.6 \mathrm{eV}(\sim 20 \%)$. Through a planoconvex $\mathrm{MgF}_{2}$ lens, VUV light is focused into the ionization zone. The sample is introduced into the photoionizer via a needle valve controlled stainless steel tube. The pressure inside the photoionizer is set at 500-1000 Pa, maintaining a sampling flow rate of $\sim 3.5 \mathrm{~cm}^{3} \mathrm{~s}^{-1}$. A set of ion immigration optics are aligned between the LPPI source and TOF-MS, and serving as an ion guiding system for higher ion transmission efficiency. The ions expelled from the photoionizer are focused by the electrostatic fields of the ion lenses, followed by injection into the TOF mass analyzer. The laboratorybuilt TOF-MS has a flight distance of $460 \mathrm{~mm}$ in the V configuration. The detailed configuration of the LPPI-MS has been described previously [26,27]. Table 1 summarizes the optimized system parameters of the instrument. All experiments are conducted at $25^{\circ} \mathrm{C}$.

\subsection{Sample preparation}

For the calibration by the fixed standard volume (FSV) method, the signal intensity responses to increasing concentrations of three analytes are obtained with liquid samples, which are prepared by diluting pure BTE 500 times with dichloromethane. $0.5 \mu \mathrm{L}$ of each diluted sample is extracted using a syringe and injected into a $120 \mathrm{~L}$ calibration chamber filled with high-purity nitrogen, corresponding to a concentration of 2 ppbv. For the calibration by the FSV method, a $0.5 \mu \mathrm{L}$ diluted sample is injected six times, and mass spectra are accordingly acquired after each injection. Five

Table 1

LPPI-MS operational parameters used in this work.

\begin{tabular}{ll}
\hline Parameter & Value selected \\
\hline Extraction field & $600 \mathrm{~V}, 58000 \mathrm{~Hz}$ \\
Acceleration field & $1500 \mathrm{~V}$ \\
Reflector & $600 \mathrm{~V}$ \\
MCP detector & $2000 \mathrm{~V}$ \\
VUV lamp & $60 \mathrm{~W}$ \\
Ionizer pressure & $500-1000 \mathrm{~Pa}$ \\
Detection cycle & $10 \mathrm{~s}$ \\
\hline
\end{tabular}



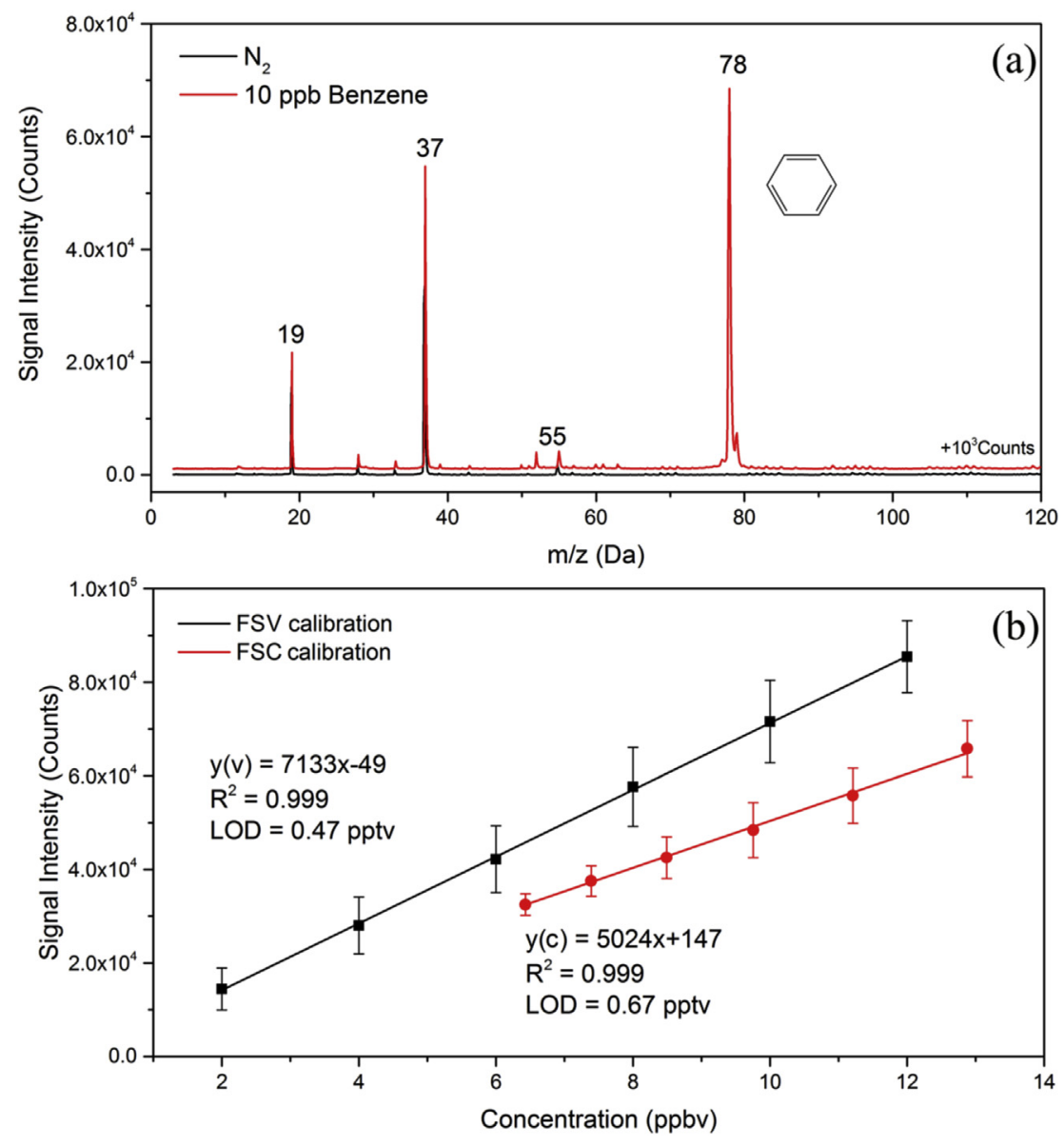

Fig. 2. Low-pressure photoionization mass spectra of nitrogen and $10 \mathrm{ppbv}$ benzene (a); linear responses of benzene under two calibration approaches in nitrogen (b).

independent measurements are conducted for each chemical. Accordingly, the average and standard deviation are calculated.

The mass spectra shown herein are obtained with gas-phase samples to avoid the formation of impurity ions in solution. The gas-phase samples are prepared by injecting $6 \mu \mathrm{L}$ of each pure chemical into a 6-L narrow-mouthed bottle filled with high-purity nitrogen and sealed with Parafilm member (Structure Probe, Inc., West Chester, PA). $5 \mathrm{~mL}$ of the gas-phase sample is added into the 120 L calibration chamber, ending up with a concentration of 10 ppbv for each sample.

For the calibration by the fixed standard concentration (FSC) method, $17 \mathrm{ppbv}$ of a gas-phase sample is injected into a $0.24 \mathrm{~L}$ cylinder. High-purity nitrogen at a flow rate of $0.2 \mathrm{~L} \mathrm{~min}^{-1}$ is continuously injected into the cylinder to dilute the 17 ppbv sample. Dynamical concentrations of the continuously diluted sample are calculated by an exponential equation described previously $[28,29]$. LPPI-MS mass spectra are acquired. Each FSC calibration starts from the highest signal intensity of sample. Five replicate batches are measured for each chemical.

Benzene (Shanghai Macklin Bio-chemical Co. Ltd., >99.5\%), toluene (Beijing Beihua Fine Chemicals Co. Ltd., >99.5\%), ethylbenzene (Shanghai Macklin Bio-chemical Co. Ltd., >99.5\%), and dichloromethane (J.T. Baker Co. Ltd., chromatographic grade) are used in the experiments. High-purity nitrogen (>99.999\%) is purchased from Beijing Haikeyuanchang Practical Gas Co. Ltd.

\subsection{Accuracy and precision}

The accuracy and precision of LPPI-MS for BTE $(\mathrm{n}=5)$ are evaluated by analyzing various sample concentrations for the FSV and FSC calibration processes. Accuracy is expressed as the percentage of the target sample concentration using the mean measured concentration $(n=5)$ from a single detection batch. Accordingly, precision is expressed as the percent relative standard deviation (RSD).

\subsection{Stability and interference experiments}

The stability of LPPI-MS is assessed by continuously measuring a BTE mixture of $1 \mathrm{ppbv}$ in $14 \mathrm{~h}$. To assess the interference from water and other protonated impurities on BTE signal intensities, the BTE mixture ( $1 \mathrm{ppbv}$ ) is measured with acetaldehyde concentrations of $5,10,15,20$, and 25 ppbv in the calibration chamber. Relative humidity $(\mathrm{RH})$ values of $10 \%, 30 \%, 50 \%, 70 \%$, and $90 \%$ are set by injecting double distilled water $\left(\mathrm{ddH}_{2} \mathrm{O}\right)$ into the calibration chamber monitored with a dewpoint monitor. The BTE mixture ( $1 \mathrm{ppbv}$ ) at different $\mathrm{RH}$ values is measured by LPPI-MS.

\section{Results and discussion}

\subsection{Mass spectrum and detection limits}

During LPPI, nonpolar VOCs (e.g., BTE) undergo direct photoionization, where a molecular ion is produced by the absorption of a single photon and the emission of an electron [30]. Fig. 2a shows the LPPI mass spectrum of benzene (ionization potential, $\mathrm{IP}=9.24 \mathrm{eV}$ ) under nitrogen, where $\mathrm{m} / \mathrm{z} 78$ corresponds to the characteristic peak $\left(\mathrm{M}^{+}\right)$. The signal intensity of $10 \mathrm{ppbv}$ benzene is 
Table 2

LODs of competitive instrumentsfor BTE at pptv and ppbv levels.

\begin{tabular}{|c|c|c|c|c|c|c|c|}
\hline \multirow[t]{2}{*}{ Number } & \multirow[t]{2}{*}{ BTE } & \multirow[t]{2}{*}{$\mathrm{m} / \mathrm{z}$} & \multirow[t]{2}{*}{$\mathrm{IP}(\mathrm{eV})$} & \multicolumn{4}{|l|}{ LODs } \\
\hline & & & & References & & FSV method & FSC method \\
\hline 1 & Benzene & 78 & 9.24 & $\begin{array}{l}\text { LPPI-MS [26] } \\
\text { HPPI-MS/RF-only Quadrupole [33] } \\
\text { PTR-MS [13] } \\
\text { TD-SPI-MS [4] } \\
\text { TD-REMPI-MS [4] } \\
\text { GC-FID [34] } \\
\text { APCI-MS [12] } \\
\text { APPI-MS [24] } \\
\text { PI-IMS [8] } \\
\text { MVP-SPI-MS [23] } \\
\text { TD-FTIR-HWG [35] } \\
\text { HiKE-IMS [9] } \\
\text { GC/MPI/TOFMS [36] } \\
\text { GC-DMS [37] }\end{array}$ & $\begin{array}{l}3 \text { pptv } \\
15 \text { pptv } \\
20 \text { pptv } \\
30 \text { pptv } \\
14 \text { pptv } \\
200 \text { pptv } \\
420 \text { pptv } \\
500 \text { pptv } \\
2 \mathrm{ppbv} \\
3 \mathrm{ppbv} \\
5 \mathrm{ppbv} \\
29 \mathrm{ppbv} \\
1.85 \mathrm{ng} \\
2 \mathrm{ng}\end{array}$ & 0.47 pptv, i.e., 0.02 pg & 0.67 pptv, i.e., 0.03 pg \\
\hline 2 & Toluene & 92 & 8.83 & $\begin{array}{l}\text { HPPI-MS/RF-only Quadrupole [33] } \\
\text { PTR-MS [13] } \\
\text { TD-SPI-MS [4] } \\
\text { TD-REMPI-MS [4] } \\
\text { GC-FID [34] } \\
\text { APCI-MS [12] } \\
\text { TG-GC/SPI-MS [38] } \\
\text { MVP-SPI-MS [23] } \\
\text { HiKE-IMS [9] } \\
\text { GC/MPI/TOFMS [36] }\end{array}$ & $\begin{array}{l}21 \mathrm{pptv} \\
15 \mathrm{pptv} \\
27 \mathrm{pptv} \\
10 \mathrm{pptv} \\
150 \mathrm{pptv} \\
390 \mathrm{pptv} \\
500 \mathrm{pptv} \\
4 \mathrm{ppbv} \\
7 \mathrm{ppbv} \\
0.02 \mathrm{ng}\end{array}$ & 0.55 pptv, i.e., 0.02 pg & 0.63 pptv, i.e., 0.03 pg \\
\hline 3 & Ethylbenzene & 106 & 8.77 & $\begin{array}{l}\text { PTR-MS [14] } \\
\text { GC-FID [34] } \\
\text { GC/MPI/TOFMS [36] } \\
\text { PI-IMS [7] }\end{array}$ & $\begin{array}{l}1 \mathrm{pptv} \\
100 \mathrm{pptv} \\
0.14 \mathrm{ng} \\
100 \mathrm{ppbv}\end{array}$ & 0.59 pptv, i.e., 0.03 pg & 0.83 pptv i.e., 0.04 pg \\
\hline
\end{tabular}

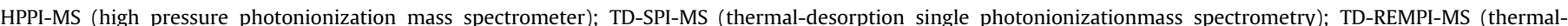

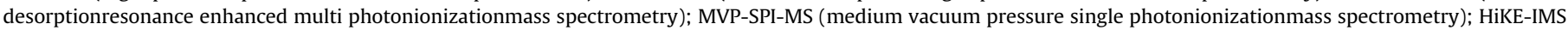

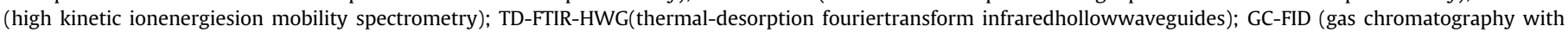
flame ionization detection); GC-DMS (gas chromatography with differential mobility spectrometry).

as high as $7 \times 10^{4}$ counts. A mass resolution of 200 (fwhm) is achieved at $\mathrm{m} / \mathrm{z} 78$. The mass peaks at $\mathrm{m} / \mathrm{z} 19,37$, and 55 correspond to $\mathrm{H}_{3} \mathrm{O}^{+}$(protonated water), $\left(\mathrm{H}_{2} \mathrm{O}\right)_{2} \mathrm{H}^{+}$, and $\left(\mathrm{H}_{2} \mathrm{O}\right)_{3} \mathrm{H}^{+}$(protonated water clusters), respectively. The protonated water clusters correspond to the photon-induced chemical ionization in the LPPI source. This phenomenon has also been observed in our recently reported measurement of other polar species, e.g., alcohols, aldehydes, ketones, and esters [31]. As shown in Fig. 2b, linear responses $\left(R^{2}=0.999\right)$ are obtained for ppbv levels of benzene from both FSV and FSC calibration methods. The slopes of the fitted lines are 7.1 and 5.0 counts/pptv, respectively. The LODs at an $\mathrm{S} / \mathrm{N}=2$ are estimated by LOD $=2 \sigma \mathrm{c} / \mathrm{h}$, where $\sigma$ is the standard deviation of the noise, $\mathrm{c}$ is the sample concentration, and $\mathrm{h}$ is the ion signal intensity $[32]$. The noise $(\sigma)$ value in the no-signal region of high-purity nitrogen background is 1.7. The LODs for LPPI-MS toward benzene (B) are calculated as 0.5 pptv (FSV method) and $0.7 \mathrm{pptv}$ (FSC method). However, for ambient measurements, the noise intensities increased by approximately 2-3 times, indicating that the method detection limit (MDL) for ambient benzene samples is 1-2 pptv. Table 2 lists the reported LODs of various instruments toward BTE.

Fig. 3a shows the mass spectrum of $10 \mathrm{ppbv}$ toluene (IP $=8.83 \mathrm{eV})$ in nitrogen. Apart from the mass peaks corresponding to protonated water and water clusters (m/z 19, 37 and 55), those observed at $\mathrm{m} / \mathrm{z} 92,91 \mathrm{Th}$ correspond to the molecular ions $\left(\mathrm{M}^{+}\right)$and dehydrogenated ones $\left([\mathrm{M}-\mathrm{H}]^{+}\right.$) of toluene, respectively, caused by photolysis (direct or photothermolysis) in the efficient photoionizer [39]. The signal intensity at $\mathrm{m} / \mathrm{z} 92$ $\left(6 \times 10^{4}\right.$ counts $)$ is as high as three-folds of that at $\mathrm{m} / \mathrm{z} 91\left(2 \times 10^{4}\right.$ counts); hence, the following linear response and LOD of toluene are measured by the signal intensity of the mass peak at $\mathrm{m} / \mathrm{z} 92$. A mass resolution of 230 (fwhm) is achieved at $\mathrm{m} / \mathrm{z} 92$. As can be observed in Fig. 3b, linear responses $\left(\mathrm{R}^{2}=0.999\right)$ are obtained from the calibration curves of toluene from the FSV and FSC calibration methods. The corresponding linear regression equations of the two curves are $\mathrm{y}(\mathrm{v})=6020 \mathrm{x}-80$ and $\mathrm{y}(\mathrm{c})=5235 \mathrm{x}+141$, respectively, indicating that the detection sensitivity of LPPI-MS for toluene (T) is 5-6 counts/pptv. The LODs of LPPI-MS for toluene are approximately 0.6 pptv by the two calibration methods (Table 2). The MDL for ambient toluene is calculated as $1-2$ pptv.

Fig. 4a shows the mass spectrum of $10 \mathrm{ppbv}$ ethylbenzene (IP $=8.77 \mathrm{eV}$ ) under nitrogen. Similar to those observed in the spectrum for toluene, mass peaks corresponding to protonated

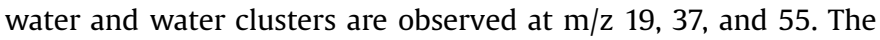
mass peaks at $\mathrm{m} / \mathrm{z} 106$ and 91 correspond to the molecular ion $\left(\mathrm{M}^{+}\right)$ of ethylbenzene and its daughter ion $\left(\left[\mathrm{M}-\mathrm{CH}_{3}\right]^{+}\right)$, respectively. As compared to benzene and toluene, ethylbenzene is easily fragmented during LPPI ionization. Consequently, the signal intensity of the molecular ion of ethylbenzene $\left(3.5 \times 10^{4}\right.$ counts $)$ is only half that of the daughter ion $\left(7 \times 10^{4}\right.$ counts). A mass resolution of 300 (fwhm) is achieved at $\mathrm{m} / \mathrm{z}$ 91. Considerable fragmentation is possibly induced by collisions between ions and photoelectrons with kinetic energies of several electron volts in the LPPI source. The fragmentation observed in LPPI might be inhibited using an LPPI source made of special materials, which generate less photoelectrons. Nevertheless, as shown in Fig. $4 \mathrm{~b}$, satisfactory linear responses $\left(R^{2}=0.999\right)$ for ethylbenzene are obtained, as evidenced by the intensity of its daughter ion $(\mathrm{m} / \mathrm{z} 91)$. Linear regression equations of the two curves are $\mathrm{y}(\mathrm{v})=5561 \mathrm{x}-3.6$ and $y(c)=4001 x+116$, respectively, indicating that the detection sensitivity for ethylbenzene for the FSV calibration method is $~ 6$ counts/pptv and that for the FSC calibration method is 4 counts/ pptv. LODs are evaluated as 0.6 pptv and 0.83 pptv by the FSV and 

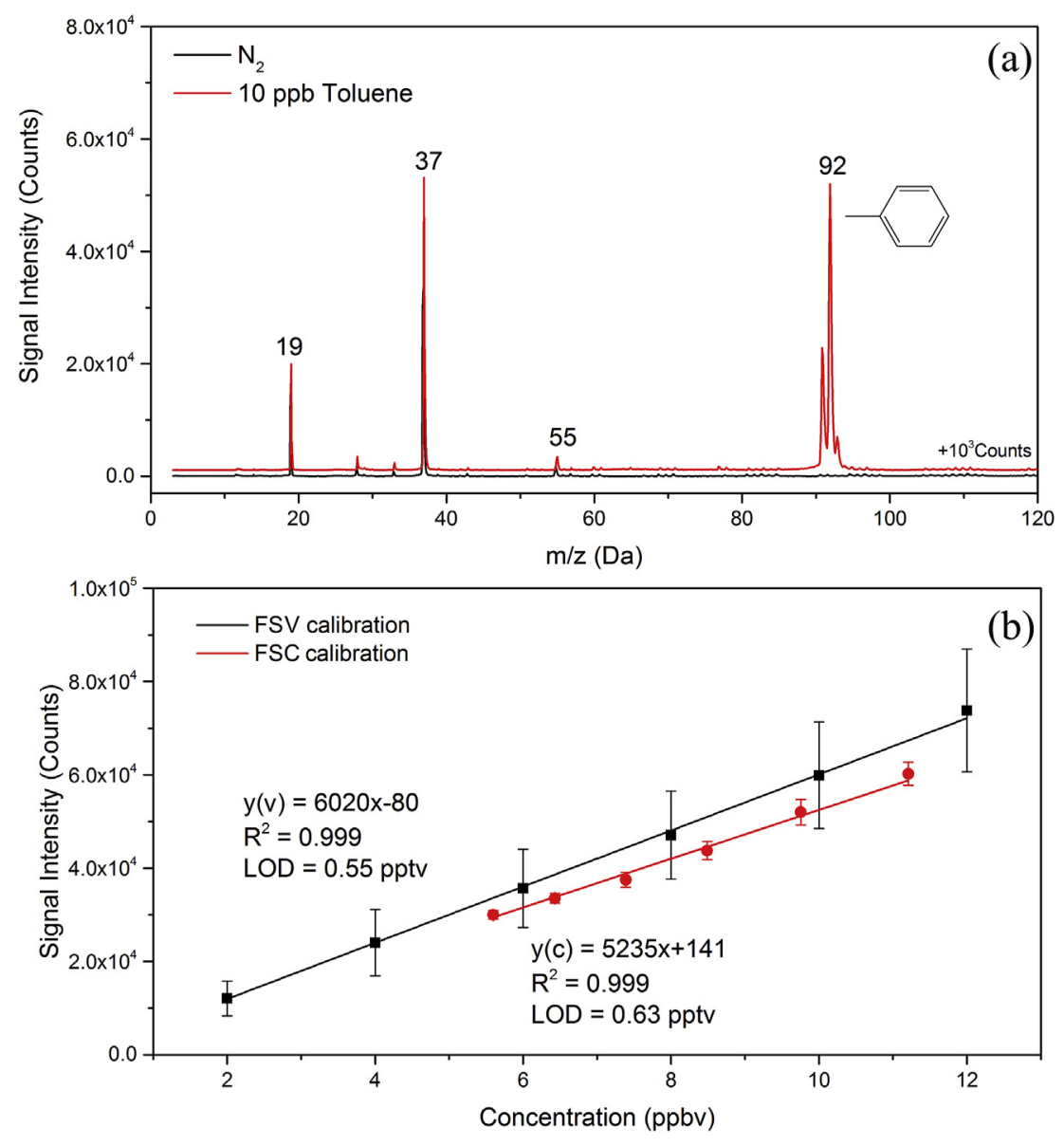

Fig. 3. Low-pressure photoionization mass spectra of nitrogen and 10 ppbv toluene (a); linear responses of toluene under two calibration approaches in nitrogen (b).

FSC methods, respectively (Table 2). Accordingly, the MDL for ambient ethylbenzene is evaluated as $1-2$ pptv.

These experimental results revealed that LPPI-MS is significantly sensitive for real-time measurements and can detect BTE samples with concentrations as low as sub-parts per trillion by volume, which exceeds other competitive techniques (e.g., TD-SPIMS and GC-FID). However, without the help of GC, LPPI-MS cannot discriminate isomers, e.g., ethylbenzene and xylene.

\subsection{Accuracy and precision}

As shown in Table 3, the accuracy of LPPI-MS ranges from 96 to $104 \%$ for BTE samples for the FSV calibration method. With increasing concentrations of BTE, the precision (RSD) of the FSV method for BTE is gradually improved from $\sim 30 \%$. The accuracy for the FSC method ranges from $97 \%$ to $102 \%$ for BTE samples. However, the precision (RSD) for the FSC method is obviously superior to that observed for the FSV method, ranging from $3 \%$ to $15 \%$. The better RSDs for the FSC method are caused not only by the higher concentrations of BTE in samples utilized in the approach but also by the superior calibration curves with less error bars (Figs. 2b, 3b and 4b). Calibration results indicated that the FSC method is more stable than the FSV method from experiments, while the sensitivity obtained by the FSV method is greater than that obtained by the FSC method. It is thought that the underestimation of the initial concentration (evaluating the dynamical concentration with an acquisition time of $10 \mathrm{~s}$ ) in the FSC method leads to lower calibration sensitivities.

\subsection{Stability and interfering factors}

The stability of LPPI-MS is evaluated by continuously measuring a 1 ppbv BTE mixture for $14 \mathrm{~h}$. Fig. 5a shows the standard deviation for measurements. The maximum standard derivation for BTE is 0.025 , indicative of the reasonably good stability of LPPI-MS. Fig. $5 \mathrm{~b}$ and $\mathrm{c}$ show the effects of interfering factors of water (under $\mathrm{RH}$ values of $10 \%, 30 \%, 50 \%, 70 \%$, and $90 \%$ ) and acetaldehyde (at 5, 10, 15 , 20, 25 ppbv), respectively, on the signal intensities of BTE. Linear regression equations of BTE are consistent to be $\mathrm{y}=0.002 \mathrm{x}+1$ from $10 \%$ to $90 \% \mathrm{RH}$. The slopes of the fitted lines for BTE are $1.1 \times 10^{-4}, 1.6 \times 10^{-4}$, and $4.8 \times 10^{-4}$, respectively, when doped with 5-25 ppbv acetaldehyde. Hence, the direct effects of water and acetaldehyde on the signal intensities of BTE are not significant. Moreover, in our previous study, the matrix effect of $\mathrm{CH}_{2} \mathrm{Cl}_{2}$ was also not observed for benzene, while a significant doping effect of $\mathrm{CH}_{2} \mathrm{Cl}_{2}$ was observed for polar compounds, e.g., water and acetaldehyde [40]. These results might indicate that BTE mainly undergo photoionization in the LPPI source. However, considering multiple collisions occurring in the LPPI source, LPPI-MS is supposed to be valid for the detection of BTE in presence of low impurity concentrations (dozens of ppbv).

The water impurity in the carrier gas affects the $\mathrm{S} / \mathrm{N}$, evidenced by the increased baseline noise. The intensities of noise at $90 \% \mathrm{RH}$ are approximately 2-3 times greater than those at 10\% RH. Hence, the LODs for BTE accordingly worsen to 1-2 pptv, which are in accordance with the MDLs under the ambient condition. These experimental results revealed that LPPI is suitable for the sub-pptv 

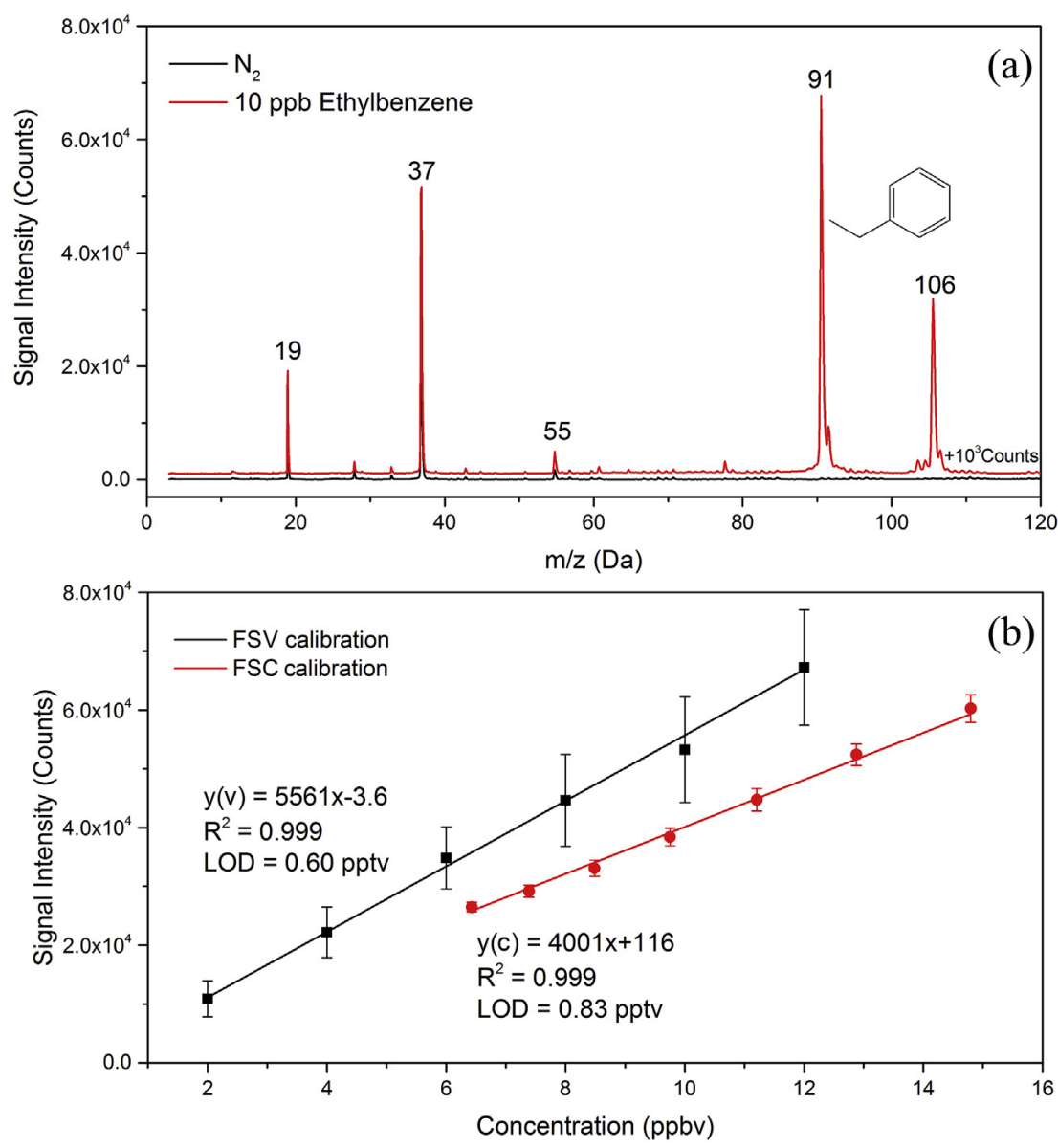

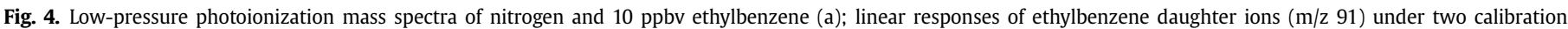
approaches in nitrogen (b).

Table 3

Accuracy and precision (RSD) of BTE in different calibration methods.

\begin{tabular}{|c|c|c|c|c|c|c|}
\hline \multirow[t]{2}{*}{ Concentration (ppbv) } & \multicolumn{2}{|l|}{ Benzene } & \multicolumn{2}{|l|}{ Toluene } & \multicolumn{2}{|l|}{ Ethylbenzene } \\
\hline & Accuracy (\%) & RSD (\%) & Accuracy (\%) & RSD (\%) & Accuracy (\%) & $\operatorname{RSD}(\%)$ \\
\hline \multicolumn{7}{|l|}{ FSV calibration } \\
\hline 2 & 101 & 31 & 101 & 31 & 98 & 28 \\
\hline 4 & 98 & 22 & 100 & 30 & 100 & 19 \\
\hline 6 & 99 & 17 & 99 & 23 & 104 & 15 \\
\hline 8 & 101 & 15 & 98 & 20 & 100 & 17 \\
\hline 10 & 100 & 12 & 100 & 19 & 96 & 17 \\
\hline 12 & 100 & 9 & 102 & 18 & 101 & 15 \\
\hline \multicolumn{7}{|l|}{ FSC calibration } \\
\hline 5.6 & - & - & 102 & 3 & - & - \\
\hline 6.4 & 100 & 7 & 99 & 3 & 102 & 3 \\
\hline 7.4 & 101 & 9 & 97 & 4 & 98 & 3 \\
\hline 8.5 & 99 & 11 & 98 & 4 & 97 & 4 \\
\hline 9.8 & 98 & 15 & 102 & 5 & 98 & 4 \\
\hline 11.2 & 99 & 11 & 102 & 4 & 99 & 4 \\
\hline 12.9 & 101 & 9 & - & - & 102 & 3 \\
\hline 14.8 & - & - & - & - & 102 & 4 \\
\hline
\end{tabular}

level detection of benzene and its derivatives under dry conditions, but the presence of high-concentration water will partly decrease the LOD of the instrument.

\section{Conclusion}

LODs on the order of sub-pptv for benzene, toluene, and ethylbenzene (or BTE) are evaluated by the FSV and FSC calibration methods. The detection sensitivity of the instrument toward BTE is 4-7 counts/pptv with excellent linear responses. Measurement accuracy for both methods is $95 \%-105 \%$; precision ranges from $3 \%$ to $15 \%$ for the FSC method and from $9 \%$ to $31 \%$ for the FSV method. These experimental results demonstrated that low-pressure photoionization mass spectrometry provides reliable responses to sub-pptv BTE under nitrogen. Under ambient moisture, water increases the noise level, affording decreased LODs (1-2 pptv). Given 

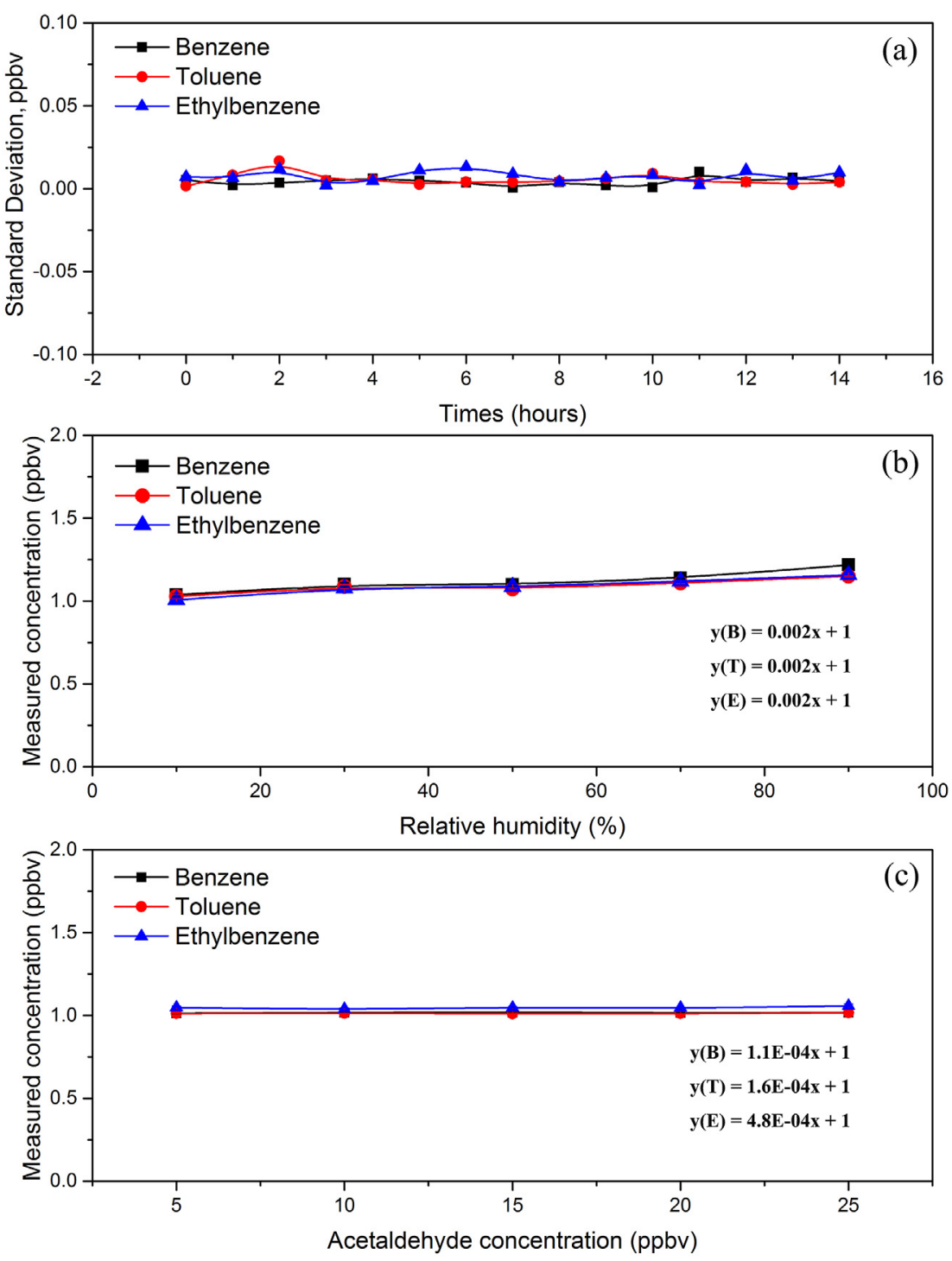

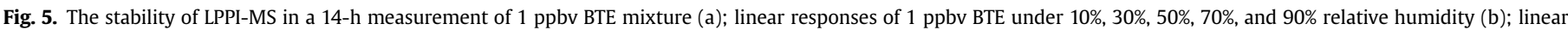
responses of 1 ppbv BTE doped with 5, 10, 15, 20, and 25 ppbv acetaldehyde (c).

the ultrasensitive detection ability, accuracy, precision, and stability of the LPPI-MS, it is anticipated to be widely applicable in laboratory medicine, environmental monitoring, drugs, foodstuffs, and other promising research fields.

\section{Acknowledgments}

This study is supported by the Strategic Priority Research Program of the Chinese Academy of Sciences (XDB05040501).

\section{Appendix A. Supplementary data}

Supplementary data related to this article can be found at http:// dx.doi.org/10.1016/j.aca.2017.01.065.

\section{References}

[1] J.K. Whitesell, J. Am. Chem. Soc. 120 (1998) 2209.

[2] K. Badjagbo, S. Sauvé, S. Moore, TrAC Trends Anal. Chem. 26 (2007) 931.

[3] K. Badjagbo, P. Picard, S. Moore, S. Sauve, J. Am. Soc. Mass Spectrom. 20 (2009) 829.

[4] J. Kleeblatt, J.K. Schubert, R. Zimmermann, Anal. Chem. 87 (2015) 1773.
[5] A.B. Kanu, P. Dwivedi, M. Tam, L. Matz, H.H. Hill, J. Mass Spectrom. 43 (2008) 1.

[6] S. Holopainen, M. Nousiainen, M.E.T. Sillanpää, O. Anttalainen, TrAC Trends Anal. Chem. 37 (2012) 124.

[7] L. Criado-Garcia, R. Garrido-Delgado, L. Arce, M. Valcarcel, Talanta 111 (2013) 111.

[8] C. Leasure, M. Fleischer, G. Anderson, G. Eiceman, Anal. Chem. 58 (1986) 2142

[9] J. Langejuergen, M. Allers, J. Oermann, A. Kirk, S. Zimmermann, Anal. Chem. 86 (2014) 11841

[10] C. Young, W. Falconer, J. Chem. Phys. 57 (1972) 918

[11] T.J. Kauppila, R. Kostiainen, A.P. Bruins, Rapid Commun. mass Spectrom. RCM 18 (2004) 808.

[12] M. Sabo, S. Matejcik, Analyst 138 (2013) 6907.

[13] C. Jordan, E. Fitz, T. Hagan, B. Sive, E. Frinak, K. Haase, L. Cottrell, S. Buckley, R. Talbot, Atmos. Chem. Phys. 9 (2009) 4677.

[14] F. Brilli, B. Gioli, P. Ciccioli, D. Zona, F. Loreto, I.A. Janssens, R. Ceulemans, Atmos. Environ. 97 (2014) 54

[15] A. Hansel, A. Jordan, C. Warneke, R. Holzinger, A. Wisthaler, W. Lindinger Plasma Sources Sci. T 8 (1999) 332.

[16] A. Jordan, S. Haidacher, G. Hanel, E. Hartungen, L. Märk, H. Seehauser, R. Schottkowsky, P. Sulzer, T.D. Märk, Int. J. Mass Spectrom. 286 (2009) 122.

[17] L. Hanley, R. Zimmermann, Anal. Chem. 81 (2009) 4174.

[18] E. Schramm, A. Kurten, J. Holzer, S. Mitschke, F. Muhlberger, M. Sklorz, J. Wieser, A. Ulrich, M. Putz, R. Schulte-Ladbeck, R. Schultze, J. Curtius, S. Borrmann, R. Zimmermann, Anal. Chem. 81 (2009) 4456.

[19] R. Zimmermann, Anal. Bioanal. Chem. 405 (2013) 6901.

[20] F. Muhlberger, K. Hafner, S. Kaesdorf, T. Ferge, R. Zimmermann, Anal. Chem. 76 (2004) 6753. 
[21] R. Zimmermann, W. Welthagen, T. Groger, J. Chromatogr. A 1184 (2008) 296. [22] C. Mullen, A. Irwin, B.V. Pond, D.L. Huestis, M.J. Coggiola, H. Oser, Anal. Chem. 78 (2006) 3807.

[23] L. Hua, Q. Wu, K. Hou, H. Cui, P. Chen, W. Wang, J. Li, H. Li, Anal. Chem. 83 (2011) 5309.

[24] H. Kersten, V. Derpmann, I. Barnes, K.J. Brockmann, R. O'Brien, T. Benter, J. Am Soc. Mass Spectrom. 22 (2011) 2070.

[25] C.Y. Liu, Y.A. Zhu, Z.Y. Zhou, J.Z. Yang, F. Qi, Y. Pan, Anal. Chim. Acta 891 (2015) 203.

[26] W.Q. Sun, J.N. Shu, P. Zhang, Z. Li, N.N. Li, M. Liang, B. Yang, Atmos. Meas. Tech. 8 (2015) 4637.

[27] Z. Li, J.N. Shu, P. Zhang, W.Q. Sun, B. Yang, H.X. Zhang, Cancer Biomarkers 16 (2016) 477.

[28] G. Gamez, L. Zhu, T.A. Schmitz, R. Zenobi, Anal. Chem. 80 (2008) 6791.

[29] J.E. Lovelock, Anal. Chem. 33 (1961) 162.
[30] J.A. Syage, J. Am. Soc. Mass Spectr. 15 (2004) 1521.

[31] Z. Li, C. Xu, J. Shu, B. Yang, Y. Zou, Talanta 165 (2017) 98.

[32] F. Muhlberger, R. Zimmermann, A. Kettrup, Anal. Chem. 73 (2001) 3590.

[33] Y. Wang, J.C. Jiang, L. Hua, K.Y. Hou, Y.Y. Xie, P. Chen, W. Liu, Q.Y. Li, S. Wang, H.Y. Li, Anal. Chem. 88 (2016) 9047.

[34] Y. Assadi, F. Ahmadi, M.R.M. Hossieni, Chromatographia 71 (2010) 1137.

[35] C.R. Young, N. Menegazzo, A.E. Riley, C.H. Brons, F.P. DiSanzo, J.L. Givens, J.L. Martin, M.M. Disko, B. Mizaikoff, Anal. Chem. 83 (2011) 6141.

[36] T. Uchimura, Y. Hironaka, M. Mori, Anal. Sci. 29 (2013) 85.

[37] S. Roetering, E.G. Nazarov, H. Borsdorf, C. Weickhardt, Int. J. Ion Mobil. Spectrom. 13 (2010) 47.

[38] M.R. Saraji-Bozorgzad, M. Eschner, T.M. Groeger, T. Streibel, R. Geissler, E. Kaisersbeiger, T. Denner, R. Zimmermann, Anal. Chem. 82 (2010) 9644.

[39] A. Leger, L. Dhendecourt, D. Defourneau, Astron Astrophys. 216 (1989) 148.

[40] J. Shu, Y. Zou, C. Xu, Z. Li, Sci. Rep. 6 (2016) 36820. 